\title{
Krebs-Killerzellen aus dem Labor
}

Stammzellforscher hoffen darauf, dass reprogrammierte Zellen in Zukunft die ethisch umstrittene Anwendung humaner embryonaler Stammzellen in Zelltherapien ersetzen können. Einer japani-

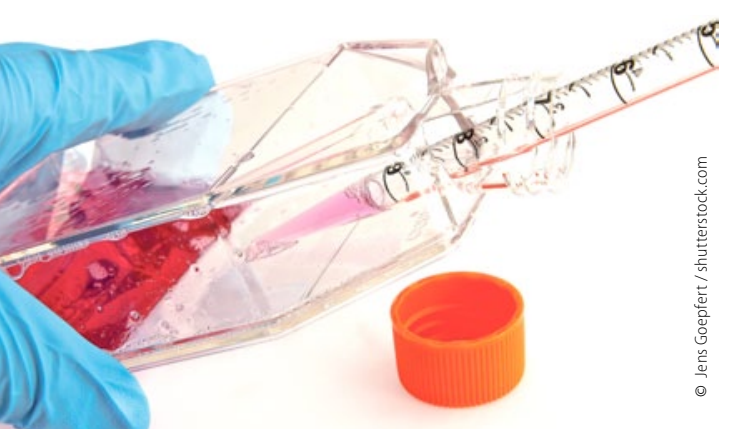

Verzicht auf embryonale Stammzellen dank reprogrammierter T-Zellen?

\section{kurz notiert}

Ausschreibung CESAR-Preis 2013

Die Central European Society for Anticancer Drug Research (CESAR)-EWIV schreibt auch im Jahr 2013 wieder den CESAR-Preis aus. Der Preis zeichnet Wissenschaftlerinnen und Wissenschaftler für Beiträge aus der translationalen Forschung zur Entwicklung antitumoraler Wirkstoffe sowohl im präklinischen als auch klinischen Bereich aus. Der Preis ist mit einer persönlichen Zuwendung von 6.000 Euro dotiert. Bewerbungen sind bis zum 31.03.2013 unter Beifügung der erforderlichen Unterlagen (siehe www.cesar.or.at) an die folgende E-Mail-Adresse zu richten: office@cesar.or.at.

\section{Helmut-Wölte-Preis 2013}

Die Helmut-Wölte-Stiftung für Psychoonkologie unterstützt die psychosoziale Versorgung von Krebspatienten. Die Stiftung hat den mit 2.500 Euro dotierten Helmut-Wölte-Preis ausgeschrieben. Gefördert werden wissenschaftliche Initiativen, bei denen die psychosoziale Versorgung von Krebspatienten und deren Angehörigen im Vordergrund steht. Ein zukunftsweisender Modellcharakter ist ebenso wichtig. Gefördert werden Programme, die sich bereits in der Phase der Realisierung befinden. Angenommen werden Bewerbungen in digitaler Form aus dem deutschsprachigen Raum. Einsendeschluss ist der 31.03.2013. Die Kontaktadresse und weitere Informationen sind im Internet abzurufen unter: www.helmut-woeltestiftung.de schen Forschergruppe gelang es nun, aus reprogrammierten krebsspezifischen zytotoxischen T-Zellen (T-Killerzellen) wiederum Killerzellen herzustellen, die ihre Krebsspezifität beibehielten und zudem länger lebten als die Ausgangszellen. Die geringe Lebensspanne konventionell hergestellter spezifischer Killerzellen war bislang ein limitierender Faktor für den erfolgreichen therapeutischen Einsatz. Für ihre Versuche verwendeten Raul Vizcardo und Kollegen reife zytotoxische TLymphozyten. Diese Immunzellen erkannten das für das Melanom spezifische Antigen MART-1.

Im ersten Schritt verjüngten die Forscher die T-Zellen, indem sie - wie der Erfinder dieser Methode, Nobelpreisträger Shinya Yamanaka, Kyoto, Japan, in seinen ersten Versuchen - mithilfe eines Virus Gene von vier verschiedenen Faktoren einschleusten. Dadurch wurden aus den T-Zellen induzierte pluripotente Stammzellen (iPS). Die Forscher wählten die Laborbedingungen im zweiten Schritt so, dass sich die iPS wieder in die melanomspezifischen T-Killerzellen verwandelten. Diese T-Zellen waren nicht nur krebsspezifisch, sondern konnten nach Antigenstimulation das Zytokin Interferon $\gamma$ ausschütten, was durch Interleukin-2 verstärkt wurde. Die Forscher glauben, dass diese Zellen nach einer Infusion im Körper länger überleben als konventionell im Labor hergestellte TKillerzellen. „Jetzt muss geprüft werden, ob die reprogrammierten Zellen spezifische Krebszellen tatsächlich abtöten können."

Peter Leiner

Vizcardo R et al. Regeneration of Human Tumor Antigen-Specific T Cells from iPSCs Derived from Mature CD8(+) T Cells. Cell Stem Cell. 2013;12(1):31-6.

\section{Zielgenauer schneiden dank Ultraschall}

Brustkrebs wird heute möglichst brusterhaltend operiert. ktuellen Daten aus England zufolge kann der Tumor aber bei $41 \%$ der Frauen nicht so vollständig herausgeschält werden, dass die Schnittränder tumorzellfrei sind. Auch durch präoperative MRT-Aufnahmen gelang es nicht, die Patientinnen besser zu selektieren und die Re-Operationsrate zu senken. Niederländische Onkologen testeten nun die intraoperative Zielsteuerung per Ultraschall: Unter sonografischer Kontrolle ließen sich die Tumoren sicherer und schonender entfernen als mit der bislang gängingen Praxis. Insgesamt wurden zwischen Oktober 2010 und März 2012134 Patientinnen mit tastbarem invasiven Brustkrebs im Frühstadium (T1-T2) in zwei Gruppen randomisiert: Bei 65 Frauen wurde der Tumor unter Ultraschallkontrolle entfernt, bei 69 anhand der präoperativ erstellten Bilder und des Tastbefundes. Unter Ultraschallkontrolle verbesserte sich die operative Präzision deutlich. Nur bei zwei Frauen (2\%) gegenüber 12 (17\%) der nach Tastbefund Operierten waren Tumorzellen in den Schnitträndern nachzuweisen. Auch die Zahl der erforderlichen Nachbehand- lungen sank. Während in der UltraschallGruppe nur sechs Frauen rebestrahlt und eine nachoperiert werden mussten, mussten sich in der Kontrollgruppe elf mehrfach bestrahlen, drei nachoperieren und fünf sogar mastektomieren lassen. Zudem war das Exzisionsvolumen trotz vergleichbarer Tumorgrößen mit dem Ultraschallverfahren im Durschnitt $19 \mathrm{~cm}^{3}$ kleiner (38 [SD 26] vs. 57 [41] $\left.\mathrm{cm}^{3} ; \mathrm{p}=0,002\right)$. Für die Studienautoren hat die ultraschallgesteuerte Resektion eindeutig Vorteile, auch wenn die Ergebnisse keine Aussagen über das kosmetische Ergebnis, die Patientenzufriedenheit und die Lokalrezidivrate zuließen. Darauf fokussieren die Wissenschaftler in einem Studien-Follow-up, dessen Ergebnisse sie für 2013 erwarten. Isamail Jatoi, San Antonio, TX/USA, bezweifelt in seinem Editorial, dass sich diese Ergebnisse auf die allgemeine Praxis übertragen lassen und belegt seine Zweifel mit einigen Argumenten. Dagmar Kraus

Krekel NMA et al. Intraoperative ultrasound guidance for palpable breast cancer excision (COBALT trial): a multicentre, randomized controlled trial. Lancet Oncol. 2013;14(1):48-54. 